Article

\title{
Mountainous City Featured Landscape Planning Based on GIS-AHP Analytical Method
}

\author{
Yanlong $\mathrm{Liu}^{1,2}$ and $\mathrm{Li} \mathrm{Li}^{2, *}$ \\ 1 School of Art, Chongqing Technology and Business University, Chongqing 400067, China; \\ puff1116@kunsan.ac.kr \\ 2 Art College, Kunsan National University, Kunsan 54105, Korea \\ * Correspondence: zoujing@kunsan.ac.kr
}

Received: 3 February 2020; Accepted: 28 March 2020; Published: 30 March 2020

\begin{abstract}
In order to take full advantage of the landscape resources in the city's featured landscape planning, and mutually integrate ecological green land with city space, this paper takes the mountainous city, Qianxi County, as the research subject to conduct an ecological sensitivity analysis with the GIS space analytical method, while adopting the Analytic Hierarchy Process (AHP) method to find a landscape resource assessment system for Qianxi County. Based on the analysis of the mountainous city landscape pattern characteristics and ecological adaptability, the paper combines with the landscape planning practice in Qianxi County and starts from the ecological pattern construction and urban landscape resource assessment to expound the methodological guidance function of the GIS-AHP analytical method for the mountainous city landscape planning. This method helps recognize the characteristics of the city landscape resources in an all-sided way that protects the city landscape, improves the use-value of the mountainous city landscape resources, integrates the city land area with the water area landscape's green land and builds an ecological, cultural, and habitable mountainous city featured landscape pattern.
\end{abstract}

Keywords: GIS space analytical method; AHP method; landscape assessment; landscape planning

\section{Introduction}

\subsection{Significance of Mountainous City Landscape Planning}

Different from the plain city in terms of the ecological environment, topography, and city form, the mountainous city has unique natural landscape resources and sophisticated ecological landscape systems. Many mountainous cities run across difficulties in development and construction, such as irrational land use structure, ecological environment deterioration, and gradual disappearance of unique landscape characteristics, which in turn devastate the city's ecological network and space texture. How to combine features in the mountainous and hilly areas, fully utilize landscape resource advantages, integrate the city's natural landscape, and shape the featured city landscape is of important significance to the city's ecology and sustainable development $[1,2]$. Throughout the development history over five thousand years in China, every city has its own development experience. The city landscape is also the expression of the city's conservation and the building of the city image. In recent years, relevant studies in China have started to focus on city featured landscape planning and construction [3]. Through the planning and research of the linear landscape, this paper considers the roads, rivers, green land, mountain land, farmland, and woodland in mountain villages and towns as a whole system. Then, the points and surfaces are connected in series with a line to form a mountain landscape with good landscape and stable ecology. 


\subsection{Landscape Resource Assessment and Landscape Planning}

As proposed by American scholar Kevin Lynch, human cognitive consensus about the city should eventually form the public image structure or factor for a sophisticated city visual landscape. The city expresses its culture or spirit through explicit images. City landscape assessment research based on city image theory may perform an effective characteristic assessment on different cognitive space factors of the landscape's public image [3,4]. Human planning considers two factors for space organization, namely the city landscape and the natural landscape, and it aims to create a harmonious spatial relationship between the city and natural landscapes. As a result, a landscape resource analysis is indispensable in the landscape planning process, while landscape resource assessment is the premise of landscape planning. Landscape planning as non-statutory planning is either a specialized project in total city planning or an independent planning project or research subject. However, no means has provided predetermined or common assessment standards and methods for city featured landscape planning. This paper refers to landscape ecology theory and takes GIS technology to discern and protect landscape factors by planning policy and land use control, thereby maintaining mountainous city landscape space structure, prohibiting landscape fragmentation, and achieving ideal landscape space patterns and landscape planning [5-7]. This paper hopes to use the analytic hierarchy process to construct the indicator system, determine the indicator weight, and assess the important factors of Qianxi County's landscape planning, to better guide the landscape construction of Qianxi County.

\subsection{GIS-AHP Analytical Method}

In order to observe the landscape space structure and dynamics, especially the sophisticated relation between the ecological environment and a broad range of human activities, GIS technology offers a very effective instrument that has already been widely applied in landscape ecology. Ecology suitability assessment applied GIS technology in practice since its inception in the 1970s [8]. After the late 1990s, GIS has been used to integrate with the ecosystem model and landscape pattern dynamic model for the convenience of multi-perspective data aggregate [9]. Moreover, GIS is also found to be useful in the computerization of land-use suitability drafting, the formation of land use decision-related public policies, and land development strategic environmental assessment in regional planning [10-13]. Besides, it is also appropriate for land suitability analytical methods with multiple indicators. To be specific, it is proper to combine the selection and assessment of agriculture ecology suitability, environmental influence, and socio-economic feasibility indicators with the latest progress of indicator weight, as well as the information and function combination process of all data sources [14]. The GIS platform can build a weighting adaptive model for ecological sensitivity assessment. The division planning of an ecological sensitive district is primarily used to control and prohibit the disorderly diffusion of the city, and prevent the deterioration of the city environment and non-urbanized areas, including the river waterfront area, mountains, hills, natural reserves, forest parks, tidal flat wetland, and basic farmland preservation areas. The ecological sensitivity assessment indicator is a group of representative factors extracted according to elements affecting or composing ecological sensitivity factors. As a factor applied in the comprehensive assessment of the research area, it reflects the general situation as per general advantages [15]. On this basis, it is essential to observe the spatial discrepancy of ecologically sensitive areas. Ecological sensitivity division is a process that divides an area into different ecological zones and manifests the possibility for each zone to encounter ecological imbalance and ecological environment issues.

The Analytic Hierarchy Process (AHP) is a simple method that makes decisions for some complicated and fuzzy problems. It especially solves improper problems for complete quantitative analysis. It is a convenient, flexible and pragmatic multi-criteria decision-making method proposed by Professor T. L. Saaty, an American operational research expert, in the 1970s. As for the systematic analysis of problems in the field of society, economy, and scientific management, people often face an intricate system short of quantitative data where multiple factors are mutually related or restricted by each other. AHP provides a new, brief and practical modeling method for the decision and sorting of 
such problems [15-17]. As a multi-criteria decision-making tool, AHP is used for tourism environmental assessment, especially on spatial or GIS-based problems. Some scholars use GIS technology as the support and the Delphi method to determine the natural, socio-economic, and ecological security factors that affect the ecological suitability of urban construction land. Additionally, AHP is used to calculate the weight of relevant impact factors. Following the principle of giving priority to ecological protection, a set of model systems and methods for assessing the ecological suitability of urban construction land has been established. Based on this, the basic ecological control area of the city in the study area is divided to provide suggestions for the rational and effective planning of urban land resources.

Both AHP and GIS technology have extensive applications in studies concerning land use suitability, city public facility site selection, and landscape resource assessment [18-21]. However, they have respective advantages and limitations. Pure GIS technology cannot process complicated weight indicators, while the AHP method cannot effectively show spatial distribution patterns. As a consequence, this research incorporates the AHP method into GIS-based ecological sensitivity analysis, by taking GIS technology to analyze landscape ecological sensitivity and taking AHP to assess ecological factors and landscape resource factors. Integrating the features of GIS and AHP fully optimizes the advantages of GIS's fast speed, high efficiency, and data superposition, and the advantages of the AHP for multi-criteria analysis and quantification, enabling landscape planning to maintain a balance between subjectivity and objectivity and improve the comprehensive assessment level of the ecological environment quality and landscape resource quality in certain areas [22]. Landscape planning should view the landscape as a complicated ecosystem, and take all values of landscape resources into account so that landscape protection, governance, and planning will be more distinctive. This research takes Qinxi County, Tangshan City of Heibei Province in China as an example to make preliminary exploration and practice in this field.

\section{Research Subject}

\subsection{Overview of Research Area}

The research is based on the cooperative project formulated by the Qianxi County Government and the local Bureau of Housing, Urban and Rural Planning. The research team that the author works in formulates specifications for the Qianxi County City Green Land System Planning (2016-2030). The research, which involves a specialized city landscape planning project, retrieves sound data sources and files from relevant departments and focuses on the guiding role of technical methods in landscape planning.

The research area of Qianxi County is located in northeastern Hebei Province at the foot of southern Yanshan Mountain and the Great Wall of China. It is the sole mountainous county in Tangshan City covering 1439 square kilometers. Qianxi County has a mountainous area of 354.4 square kilometers, accounting for $24.6 \%$ of the gross area; a hilly area of 701.2 square kilometers, accounting for $48.7 \%$ of the gross area; a river and reservoir area of 163.9 square kilometers, accounting for $11.5 \%$ of the gross area. Qianxi County abounds in water resources. Main rivers include the Luan River, Sa River, Heng River, Chang River, Qing River, and Huanxiang River. Qianxi County has rich vegetation resources, with a coverage of over $80 \%$ in the north and around $60-70 \%$ in the south [23].

Qianxi County has a favorable ecological environment, harmonious natural landscape, and humanistic landscape, abundant resources rich in feature and category, and supreme tourism resource combinations. According to the statistics, there are more than 100 valuable landscape resources appropriate for development (as shown in Figure 1). The most beautiful mountain landscape is situated in the middle of Qianxi County in an east-west direction comprising the Jingzhongshan Scenic Spot, Wuhu Mountain, Southern Taiping Mountain, and Fenghuang Mountain alongside the mainline of Sanwu Road. The most beautiful water landscape is also situated in the middle of Qianxi County in a north-south direction from Saishanghai (formerly Panjiakou Reservoir) to Lixiang Lake (formerly Daheiting 
Reservoir) and Qianxi downtown alongside the Luan River. At the northern county border, there are a number of historical relics along the Great Wall from Longjing Pass to Xifengkou, Qingshan Pass and Cayazikou, and most of them are humanistic and historical tourism resources [24,25]. As of 2014, Qianxi County has two national 4A-level scenic spots in Jingzhongshan and Qingshanguan, two national 3A-level scenic spots in Wuhu Mountain and Xifeng Xiongguan Dadao Garden. Xifengkou Great Wall Anti-Japanese War Ruin has become a national red tourism classic scenic spot. Qianxi County was rated as a national demonstration county of leisure agriculture and rural tourism. The fishermans' water village was rated as a national demonstration site of leisure agriculture and rural tourism. Four scenic spots such as Xifengkou Chestnut Grand View Garden were rated as provincial agricultural tourism demonstration sites. In December 2018, Qianxi County was awarded the title of "National Forest Tourism Demonstration County" by the State Forestry Administration.

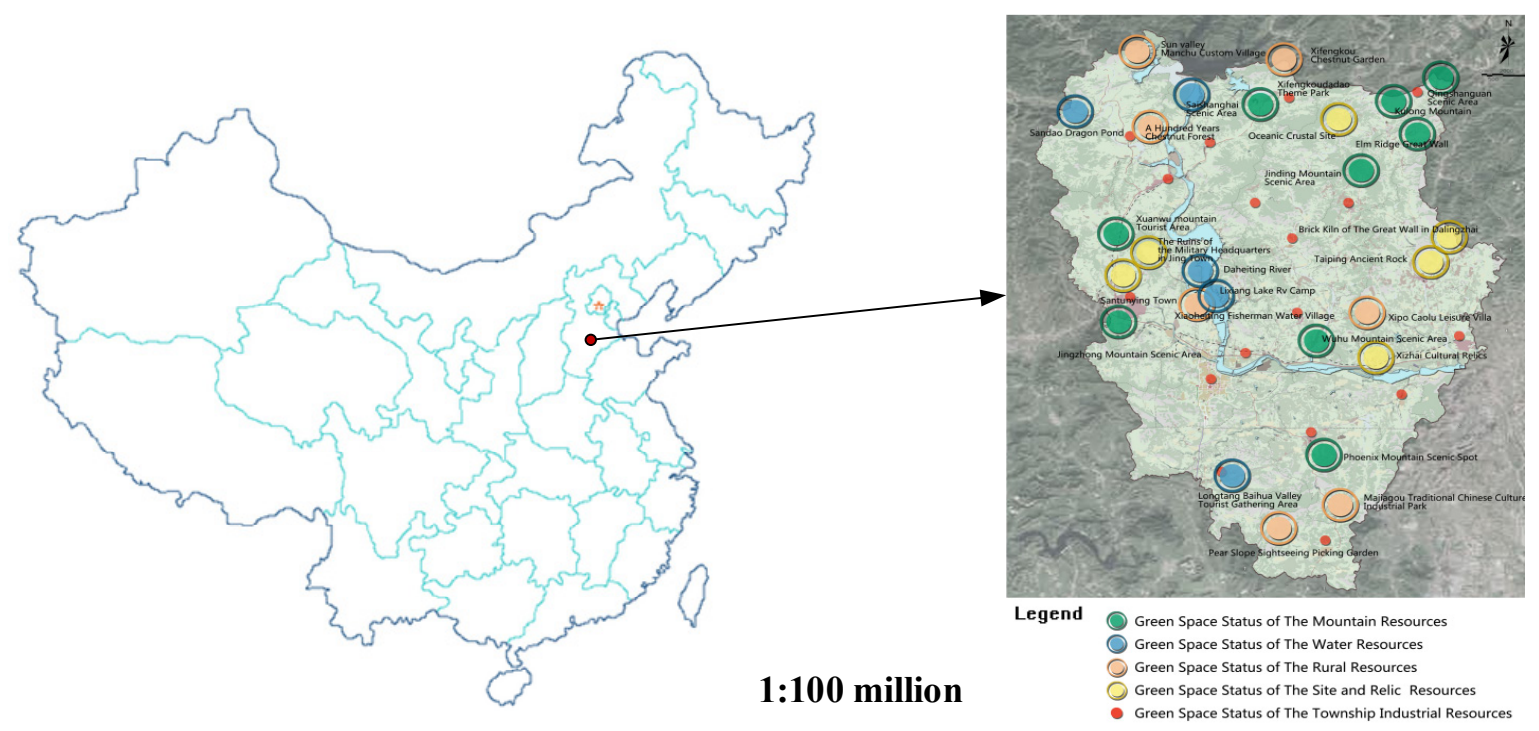

Figure 1. Green Land Condition in the County.

\subsection{Data Source and Data Processing}

Primitive research data in the research area in Qianxi County comes from land coverage information retrieved by Landsat 8 remote sensing image in 2017 (with a space resolution of $15 \times 15 \mathrm{~m}$. source: http://www.gscloud.cn/). Landsat 8 is the eighth satellite of the U.S. Landsat Program. It was successfully launched by Atlas-V rocket at Vandenberg Air Force Base, California on February 11, 2013. Landsat 8 carries a land imager and thermal infrared sensor. Landsat remote sensing image data can be used in many research fields such as natural resource protection, energy exploration, environmental management, and natural disaster monitoring. After a series of pre-processing procedures including geometric correction, atmospheric correction, and rectification under the support of the ENVI5.1 platform, the data is used as the spatial data in further analysis. Research data about gradient and altitude in the research area is collected by a digital elevation model (DEM) from GS Cloud (with a space resolution of $30 * 30 \mathrm{~m}$. source: http://www.gscloud.cn/). According to China's actual landform characteristics and national 1:1 million landform mapping specifications, it is stipulated that the low altitude is less than $1000 \mathrm{~m}$, and the middle altitude is $1000-3500 \mathrm{~m}$, and the high altitude is $3500-5000 \mathrm{~m}$, and the extremely high altitude is greater than $5000 \mathrm{~m}$. In the analysis, the ArcGIS10.3 software is used to load the 3DAnalyst module and import DEM data. The reclassify function is used to divide DEM data into two levels of middle altitude and high altitude. With the help of 15 1:1 million landform map classification systems, the relative heights are adopted in the process of updating and producing the landform maps and the relief amplitude is used as the first-level grading index. Based on this, the landform can be divided into seven levels, and the relief amplitude result is automatically calculated by using the Raster Calculator tool in the Spatial Analyst module. Based on the absolute altitude and relief data in the research area, 
the basic landform types can be analyzed. Additionally, the table of basic landform types in this area can be derived, and the overlay analysis is performed in ArcGIS after being determined.

Other materials about the research area come from the Qianxi County Urban-Rural Overall Planning (2013-2030) enacted by Qianxi County People's Government, Qianxi County Urban-Rural Green Land Systematic Planning (2016-2030) compiled by the Bureau of Housing, Urban and Rural Planning, and the tourism development overall planning of Qianxi County in Hebei Province (2016-2025) compiled by the Tourism Development Research Center of Yanshan University.

\section{Methods}

This research conducts considerable field surveys and analyses on the research area in this project and cooperates with relevant experts to select assessment indicators to build the indicator system. Based on the technical platform of ArcGIS, the research performs an ecological sensitivity analysis on Qianxi County. By analyzing the topography and other ecological factors of Qianxi County, the research finally grades the sensitivity of every single factor and assesses its weight for the superposition of single factor layers. Subsequently, the research uses the AHP to assess the distribution characteristics and features of natural landscape resources and human resources. To better protect landscape resources and more comprehensively investigate the landscape pattern in the research area (as shown in Figure 2), the paper not only observes ecological factors but also takes cultural and socio-economic conditions into account [26-29].

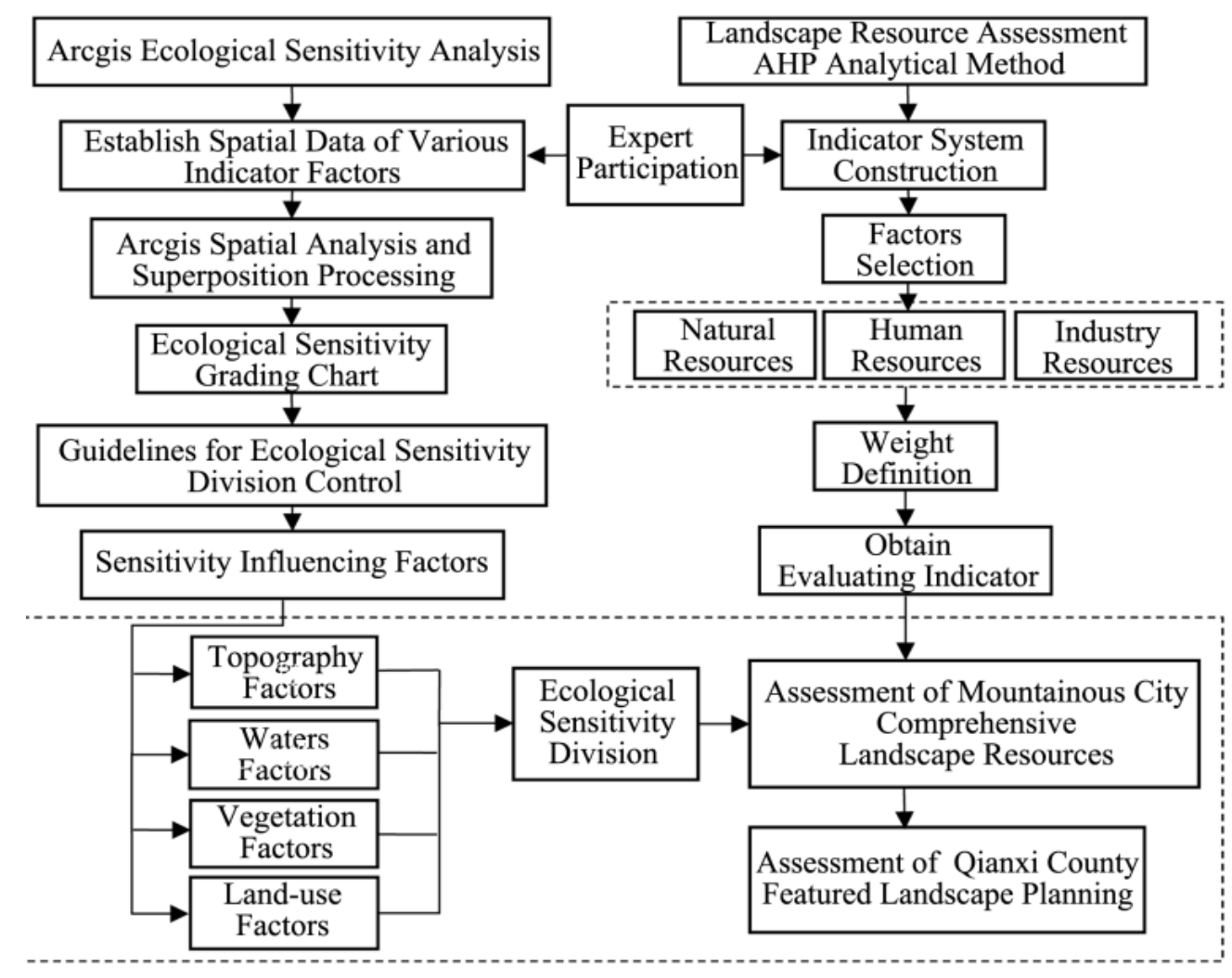

Figure 2. GIS-AHP analytical method-based featured landscape planning technical framework. 


\subsection{Ecological Sensitivity Analysis}

\subsubsection{Assessment Indicator System Construction}

Qianxi County possesses extremely superior ecological environment resources. Verdant mountains, karst water, forests, orchards, and countryside altogether constitute the framework of the local environment. In general, Qianxi County enjoys strong comparative advantages. According to the unique mountainous ecological environment and distribution of plentiful resources in Qianxi County, the paper consults relevant literature to choose four types of influential factors covering topography factors, waters factors, vegetation factors, and land-use factors to establish the indicator system for ecological sensitivity assessment and respectively assigns all factors [30,31]. Ecological factors are mutually affected and besides, human activities may also directly intervene and damage these factors.

\subsubsection{Single Factor Layer Formation}

From the macro perspective, the research expresses the altitude of the site based on DEM. DEM is a solid ground model that uses a set of ordered numerical arrays to represent ground elevation. The limited terrain elevation data is used to realize the digital simulation of the ground terrain (that is, the digital expression of the terrain surface shape). The land data in this paper is obtained from the existing topographic map by the grid point reading method and semi-automatic acquisition by the scanner. Then, DEM is generated through interpolation. The retrieved DEM data is converted to the county elevation chart after being computed and analyzed. It is also feasible to continually retrieve gradient data in ArcGIS. To be specific, the first step is to choose the "spatial analyst instrument"--"surface analysis"-"gradient" in ArcToolbox, and open the gradient dialog box to input the data. In this way, the gradient chart will be drawn out. The second step is to retrieve the local water network by "hydrological analysis" in "spatial analyst instrument" and input buffer distance in "analyst instrument"-“neighborhood analysis"-_"multi-ring buffer zone" to obtain the drainage distance chart in the research area. The hydrological analysis shows that the watershed area in some of the research area is large, and there are no measured contours or elevation points in the whole watershed. Thus, it can intuitively express the topographic relief information of the watershed. The DEM data in this paper comes from the National Basic Geographic Information Center, with an accuracy of 1:50 million and a resolution of $25 \mathrm{~m} \times 25 \mathrm{~m}$. According to land use conditions in the research area, the land in Qianxi County falls into six types including forest land, grassland, arable land, waters, construction land, and unused land. Finally, the research applies ENVI software in unsupervised classification to retrieve city green land patches information and generate a land-use chart (as shown in Figure 3) [31,32]. Unsupervised classification is the process of searching and defining naturally similar spectral clusters in multispectral images. It does not need to acquire prior knowledge of image landmarks, only rely on the spectral information of different types of landmarks on the image for feature extraction. Then, the differences in characteristics are counted to achieve the purpose of classification. Finally, the actual attributes of each category that has been classified are confirmed. At present, ISODATA, K-Mean, and chain methods are more commonly used for unsupervised classifiers. ENVI includes ISODATA and K-Mean methods. It needs to open ENVI and select the main menu-> Classification-> Unsupervised-> IsoData or K-Means. The IsoData is selected here. When selecting a file, the spatial or spectral clipping region can be set. Post-classification processing includes many processes that are optional, such as the change of the category color, statistical analysis of classification, small spot processing, and grid vector conversion. 


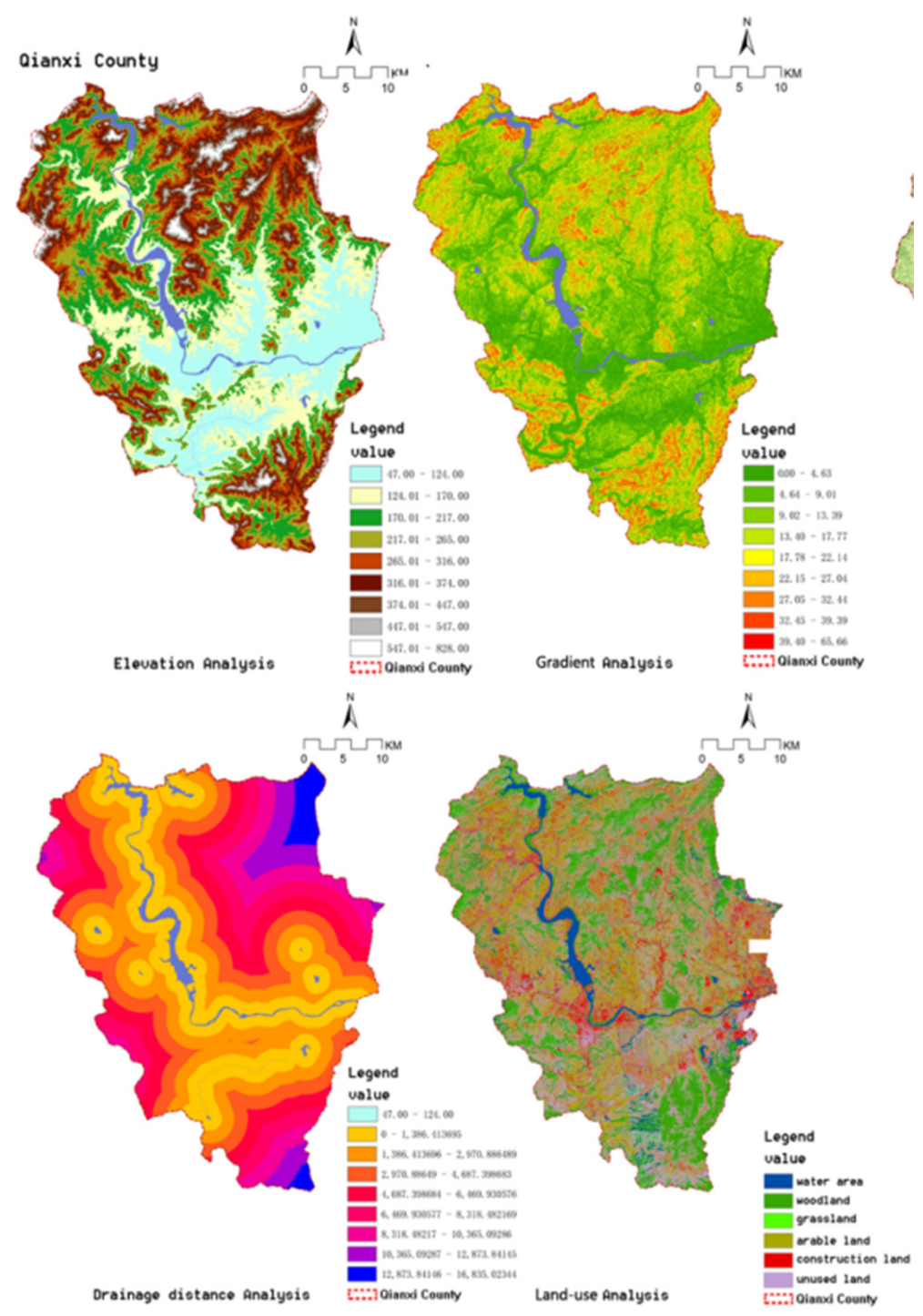

Figure 3. Single factor land-use chart.

\subsubsection{Ecological Sensitivity Assessment}

The deterioration of the ecological environment of mountain villages and towns is becoming more and more serious. In addition to the complicated terrain, ecological sensitivity and vulnerability are more intense. The assessment of ecological sensitivity can reflect the difficulty and possibility of the occurrence of ecological and environmental problems when the regional ecosystem encounters disturbances. It is also used to characterize the possible consequences of external disturbances and provide a basis for ecological function zoning. Factor superposition analysis overlays all factors to compute the maximum. Following the procedure of "spatial analyst"-"superposition analysis"-_weighted sum"-"input raster" in ArcGIS spatial analysis, the research computes the weighted sum of ecological sensitivity single factor indicator and weight, as well as adds the single factor analysis chart into the computation process to draw the ecological sensitivity analysis chart (as shown in Figure 4) [31]. Next, the research sorts out the proportion of each sensitivity area in the gross research area (as shown in Table 1). 


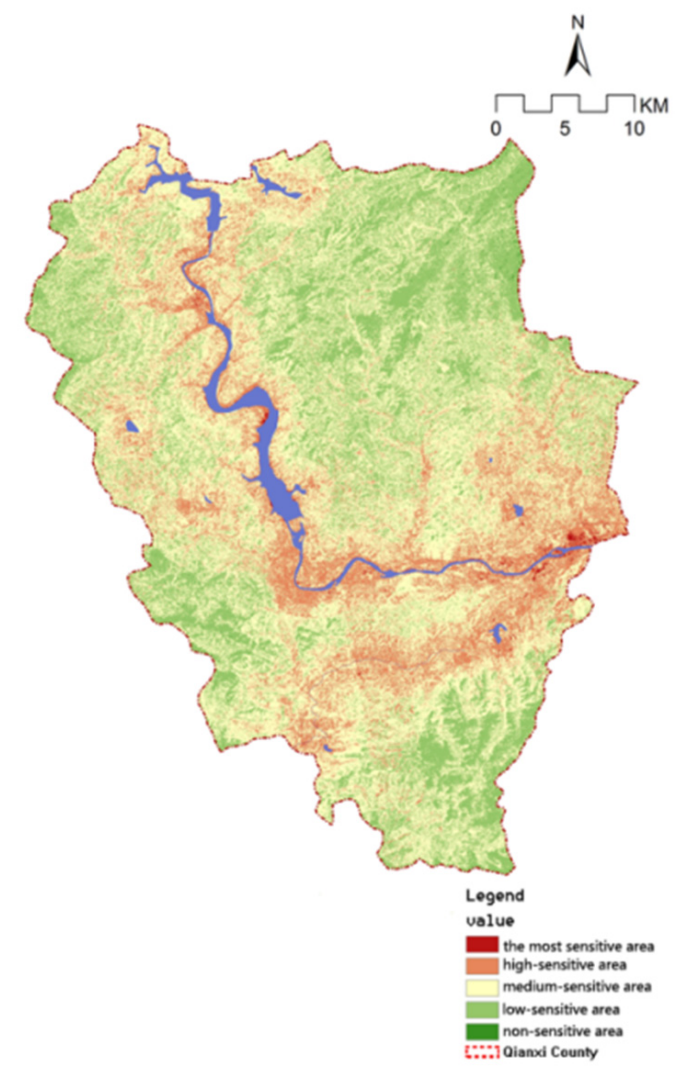

Figure 4. Ecological sensitivity analysis chart.

Table 1. Ecological sensitivity analysis.

\begin{tabular}{ccc}
\hline Classification & Dimensions $/ \mathbf{k m}^{\mathbf{2}}$ & Proportion \\
\hline the most sensitive area & 31 & 2.06 \\
high-sensitive area & 24 & 16.15 \\
medium-sensitive area & 81 & 54.27 \\
low-sensitive area & 41 & 27.44 \\
non-sensitive area & 11 & 0.08 \\
\hline
\end{tabular}

As proven by the analysis results, the area in the middle part of Qianxi County in the north-south direction from Daheiting Reservoir to other waterfront areas, plain and hill areas is the most sensitive and high-sensitive area. Because of the low altitude, these areas are mostly exploited as arable land and construction land, they frequently hold tourism activities and maintain high sensitivity towards city development and construction. This is also the reason why the ecological environment here is very vulnerable. There are plenty of humanistic and historical tourist spots such as the relic of the Great Wall in northern Qianxi County in the high-sensitive and medium-sensitive area, covering Sa River, Heng River, Chang River, Qing River, and Huanxiang River. As a result of the poor resistance to external intervention and the vital role in recovering the ecological functions of the most sensitive area, the area should be prudently treated in the development process. The low-sensitive and non-sensitive area is primarily forest land, including barren mountain, arable land, and waste farmland. With the high altitude of a few natural landscape resources and less human intervention, the area is suitable for development and construction.

\subsection{Landscape Resource Assessment}

Relying on the natural resources and human history with abundant deposits and unique landscape, Qianxi County is devoted to the building of four major cultures including religious culture, Luan River 
culture, the Great Wall culture, and chestnut culture. At present, in addition to built-up national water conservancy tourist attraction, provincial tourist attraction and other scenic spots, there also exists national-level leisure agriculture and rural tourism demonstration sites. Each town has distinctive industry functions. All towns in Qianxi County are divided into four types, namely a comprehensive town, industry and mining town, ecological tourism town, and featured forest-fruit town. In particular, some towns even preserve featured scenic spots and historical relics.

In this project, the author takes charge of landscape resource investigation and collation work, and experts classify and assess all sorts of grand land in Qianxi County. Consequently, this project makes an overview assessment of natural resources, human resources, and industry resources, as well as has a comprehensive understanding of overall resources inside the county. The selection of indicators must be representative and the number must be moderate. Including too many indicators is likely to negatively affect the accuracy of the results. Additionally, the construction of the indicator system must have a sense of hierarchy, to form a complete assessment system. Landscape development is a dynamic process. The selected indicators should change in time, and data on the development level of these indicators can be obtained. The indicator system established in this way can reflect the current situation and future trends of the development of the residential landscape at each stage. Therefore, this paper combines the relevant theories and materials of the mountain landscape, analyzes the constituent elements of the residential landscape, and selects some representative indicators.

\section{(1) Indicator System Construction}

The Delphi method is used to solicit expert opinions, and a total of 14 experts are consulted to score the various indicators. The questionnaire will be used to calculate the weight of each factor in the assessment of landscape resources in Qianxi County Scenic Spot. According to the relevant standards of the AHP, the relative importance of different factors at the same level is compared one by one. Regarding the nature of the system, the elements in the system are arranged in an orderly multi-level analysis structure according to their membership and related relationships. In accordance with expert scoring results, the paper then calculates the average score of each indicator and forms the final indicator system (as shown in Table 2).

Based on comprehensive analysis results, the research applies the expert scoring method in the judgment matrix assignment and consistency test at the criterion and indicator layer and derives the judgment matrix and indicator weight pursuant to the expert scoring results.

By reference to the AHP proposed by Saaty in 1980, the research summarizes the specific flow of this analytical method as shown below in Table 3 [33]. The hierarchy structure reflects the relationship between factors. However, the proportion of different criteria at the criterion layer in objective measurement is not the same. In the mind of decision-makers, each criterion accounts for a specific proportion. In the construction of the landscape visual assessment system, the factors that affect the quality of the landscape vision are decomposed into several layers from top to bottom according to their own attributes. The lower-level factors will more or less affect the upper-level factors, but at the same time, the upper-level factors will also be restricted by the lower-level factors. The basic principle of the AHP is to treat the complex problem to be studied as a system, which can decompose the problem that cannot be completely quantitatively analyzed into several combination factors. By analyzing the affiliation relationship of each factor, it is divided into different levels, and then a hierarchical structure model is constructed. Because of the many factors considered in landscape planning, the target system has hierarchically staggered assessment indicators, and the target value is difficult to describe quantitatively. Choosing the AHP can standardize and quantify people's perceptual thinking and subjective judgments, thereby simplifying system analysis and calculation. It can greatly reduce the influence of uncertain factors and improve the accuracy of the results. 
Table 2. Indicator System Table.

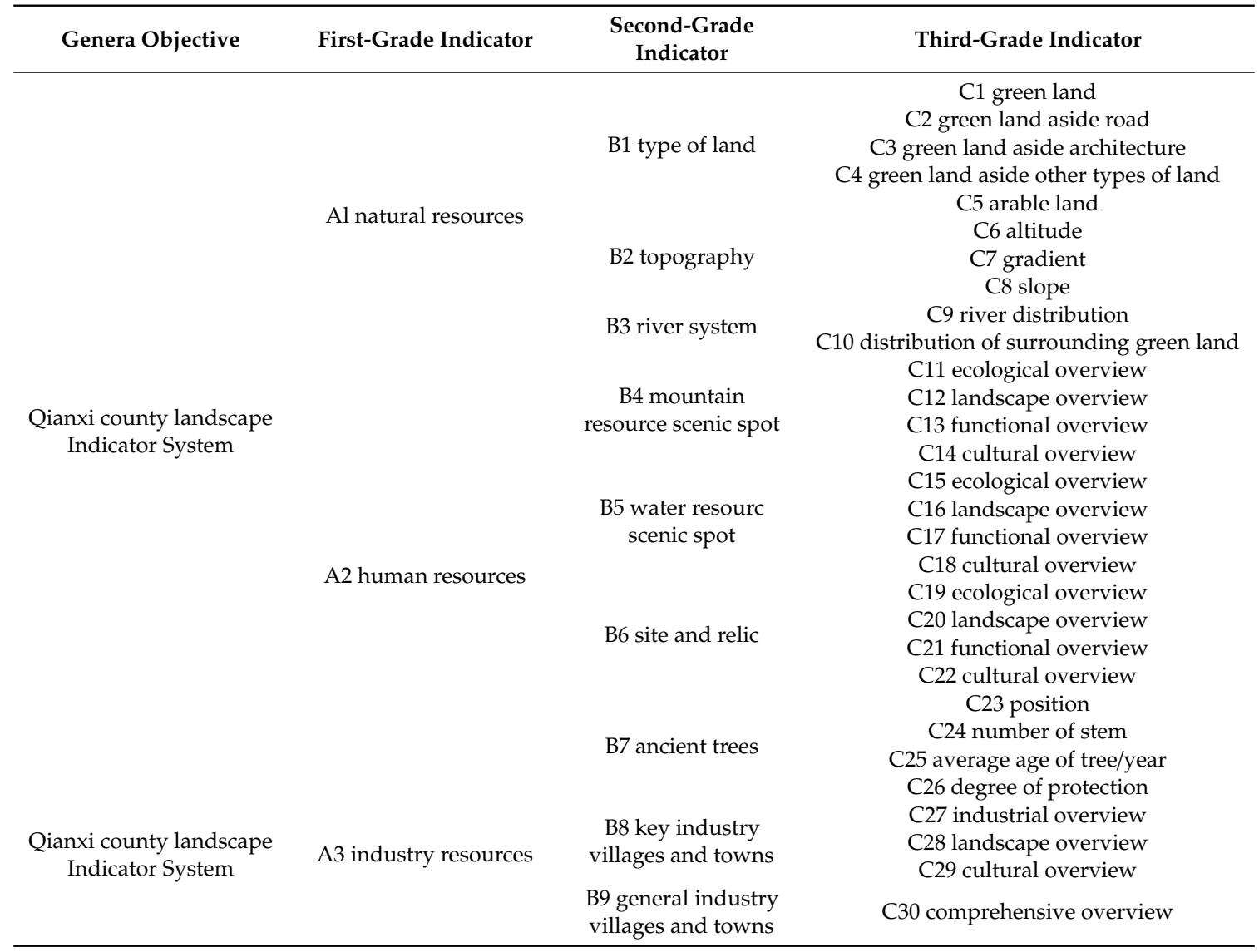

Table 3. aij Value Size, Scale and Implication.

\begin{tabular}{cc}
\hline Scale & Implication \\
\hline 1 & The two factors are of equal importance \\
3 & Of two factors, the former is slightly more important than the latter \\
5 & Of two factors, the former is obviously more important than the latter \\
9 & Of two factors, the former is greatly more important than the latter \\
$2,4,6,8$ & Of two factors, the former is extremely more important than the latter \\
reciprocal & Median of adjacent judgment
\end{tabular}

Judgment matrix A meets the condition of (i) aij $>0$, (ii) aji $=1 / a i j,(i, j=1,2, \ldots n$ ).

$\lambda_{\max }>n$ is assumed to be tenable when and only when $n$-rank reciprocal matrix $\mathrm{A}$ is consistent with the corresponding largest eigenvalue as $\lambda_{\max }=n$, and the reciprocal matrix is inconsistent. Accordingly, it is feasible to test whether judgment matrix $\mathrm{A}$ is a consistent matrix according to whether $\lambda \max$ is equal to $n$.

Following the formula from the literature [34-36], the research summarizes the following judgment matrix consistency test procedures.

(1) Calculate consistency indicator CI

$$
C I=\frac{\lambda_{\max }-n}{n-1}
$$

Wherein $n$ is the number of row and column of a judgment matrix. If $C I=0$, the judgment matrix has full consistency, or otherwise it should be judged according to consistency ratio $C R$. 
(2) Find corresponding average random consistency indicator RI. The value of RI in the condition of $n=1,2 \ldots 9$ is as shown in Table 4 .

Table 4. RI Value.

\begin{tabular}{cccccccccccccc}
\hline $\boldsymbol{n}$ & $\mathbf{1}$ & $\mathbf{2}$ & $\mathbf{3}$ & $\mathbf{4}$ & $\mathbf{5}$ & $\mathbf{7}$ & $\mathbf{8}$ & $\mathbf{9}$ & $\mathbf{1 0}$ & $\mathbf{1 1}$ & $\mathbf{1 2}$ & $\mathbf{1 3}$ & $\mathbf{1 4}$ \\
\hline $\mathrm{RI}$ & 0 & 0 & 0.58 & 0.90 & 1.12 & 1.32 & 1.41 & 1.45 & 1.49 & 1.51 & 1.54 & 1.56 & 1.58 \\
\hline
\end{tabular}

(3) Calculate consistency ratio $C R$

$$
C R=\frac{C I}{R I}
$$

The consistency of the judgment matrix is acceptable in the case of $C R<0.10$. Or otherwise, proper revision should be made in the judgment matrix. If $C R>0.10$, the data will not generate meaningful outcomes unless re-examined.

(2) Data Analysis

The above section presents the weight vector of a group of factors against certain factors in the above level. In order to obtain the ranking weight of each factor for the objective, especially factors at the bottom level in the project, it is essential to choose a proper proposal in the next step. Gross ranking weight is summed by the weight under a single criterion. Finally, the research calculates the weight and comprehensive value of all indicators in the Qianxi County city landscape value assessment (as shown in Table 5).

Table 5. Qianxi County City Landscape Value Assessment Results.

\begin{tabular}{|c|c|c|c|c|c|c|c|c|}
\hline General Objective & $\begin{array}{l}\text { First- } \\
\text { Grade } \\
\text { Indicator }\end{array}$ & $\begin{array}{l}\text { First- } \\
\text { Grade } \\
\text { Weight }\end{array}$ & $\begin{array}{l}\text { Second- } \\
\text { Grade } \\
\text { Indicator }\end{array}$ & $\begin{array}{l}\text { Second- } \\
\text { Grade } \\
\text { Weight }\end{array}$ & $\begin{array}{l}\text { Second- } \\
\text { Grade } \\
\text { Gross } \\
\text { Weight }\end{array}$ & $\begin{array}{l}\text { Third- } \\
\text { Grade } \\
\text { Indicator }\end{array}$ & $\begin{array}{l}\text { Third- } \\
\text { Grade } \\
\text { Weight }\end{array}$ & $\begin{array}{c}\text { Third- } \\
\text { Grade } \\
\text { Gross } \\
\text { Weight }\end{array}$ \\
\hline \multirow{10}{*}{$\begin{array}{c}\text { Qianxi County } \\
\text { City Landscape Value } \\
\text { Assessment Results }\end{array}$} & \multirow{10}{*}{ A1 } & \multirow{10}{*}{0.5389} & \multirow{6}{*}{ B1 } & \multirow{6}{*}{0.1638} & \multirow{6}{*}{0.0883} & $\mathrm{C} 1$ & 0.4161 & 0.0367 \\
\hline & & & & & & $\mathrm{C} 2$ & 0.2618 & 0.0231 \\
\hline & & & & & & $\mathrm{C} 3$ & 0.1611 & 0.0142 \\
\hline & & & & & & $\mathrm{C} 4$ & 0.0986 & 0.0087 \\
\hline & & & & & & C5 & 0.0624 & 0.0055 \\
\hline & & & & & & C6 & 0.5869 & 0.1704 \\
\hline & & & \multirow[t]{2}{*}{ B2 } & \multirow[t]{2}{*}{0.5389} & \multirow[t]{2}{*}{0.2904} & $\mathrm{C} 7$ & 0.3238 & 0.0940 \\
\hline & & & & & & $\mathrm{C} 8$ & 0.0893 & 0.0259 \\
\hline & & & \multirow{3}{*}{ B3 } & \multirow{3}{*}{0.2973} & \multirow{3}{*}{0.1602} & C9 & 0.75 & 0.1202 \\
\hline & & & & & & $\mathrm{C} 10$ & 0.25 & 0.0401 \\
\hline \multirow{20}{*}{$\begin{array}{c}\text { Qianxi County } \\
\text { City Landscape Value } \\
\text { Assessment Result }\end{array}$} & \multirow{16}{*}{ A2 } & \multirow{16}{*}{0.2973} & & & & $\mathrm{C} 11$ & 0.4824 & 0.0659 \\
\hline & & & \multirow{3}{*}{ B4 } & \multirow{3}{*}{0.4598} & \multirow{3}{*}{0.1367} & $\mathrm{C} 12$ & 0.2718 & 0.0372 \\
\hline & & & & & & $\mathrm{C} 13$ & 0.1575 & 0.0215 \\
\hline & & & & & & $\mathrm{C} 14$ & 0.0883 & 0.0121 \\
\hline & & & \multirow{5}{*}{ B5 } & \multirow{5}{*}{0.2723} & \multirow{5}{*}{0.0810} & C15 & 0.5192 & 0.0420 \\
\hline & & & & & & $\mathrm{C} 16$ & 0.2596 & 0.0210 \\
\hline & & & & & & $\mathrm{C} 17$ & 0.1402 & 0.0113 \\
\hline & & & & & & C18 & 0.0810 & 0.0066 \\
\hline & & & & & & C19 & 0.5674 & 0.0304 \\
\hline & & & \multirow{3}{*}{ B6 } & \multirow{3}{*}{0.1803} & \multirow{3}{*}{0.0536} & C20 & 0.2374 & 0.0127 \\
\hline & & & & & & $\mathrm{C} 21$ & 0.1236 & 0.0066 \\
\hline & & & & & & $\mathrm{C} 22$ & 0.0716 & 0.0038 \\
\hline & & & \multirow{5}{*}{ B7 } & \multirow{4}{*}{0.0876} & \multirow{4}{*}{0.0260} & $\mathrm{C} 23$ & 0.5306 & 0.0138 \\
\hline & & & & & & $\mathrm{C} 24$ & 0.2445 & 0.0064 \\
\hline & & & & & & $\mathrm{C} 25$ & 0.1531 & 0.0040 \\
\hline & & & & & & $\mathrm{C} 26$ & 0.0718 & 0.0019 \\
\hline & \multirow{4}{*}{$\mathrm{A} 3$} & \multirow{4}{*}{0.1638} & & & & $\mathrm{C} 27$ & 0.5714 & 0.0624 \\
\hline & & & B8 & 0.6667 & 0.1092 & $\mathrm{C} 28$ & 0.2857 & 0.0312 \\
\hline & & & & & & C29 & 0.1429 & 0.0156 \\
\hline & & & B9 & 0.3333 & 0.0546 & C30 & 1.0000 & 0.0546 \\
\hline
\end{tabular}


Here are the gross sorting test and consistency test results:

$$
\begin{aligned}
& C I=\sum_{j=1}^{3} w_{j} C I_{j}=0.5389 * 0.0046+0.2973 * 0.0292+0.1638 * 0.00=0.0112 \\
& R I=\sum_{j=1}^{3} w_{j} R I_{j}=0.5389 * 0.58+0.2973 * 0.9+0.1638 * 0.00=0.5801 \\
& C R=\frac{C I}{R I}=\frac{0.0112}{0.5801}=0.01931
\end{aligned}
$$

Considering $C R=0.01931<0.1$, the gross level satisfies consistency test requirements. This implies the applicability of the weight.

\section{Results}

\subsection{Assessment of Mountainous City Comprehensive Landscape Resources}

As shown by the above analysis and in view of the close intimacy between natural resources and the natural environment, attention should be first paid to the protection of the natural landscape, and later to human resources and industry resources. As to the assessment of natural landscape resources, what counts the most is the topography and river distribution. Regarding the assessment of human resources, what counts the most should be the mountain resources and water resources. Site and relic and ancient trees should be examined as a secondary priority owing to their scattered distribution inside the county.

Planning suggestions may be raised in combination with the assessment results of natural resources, human resources, and industry resources. On the other hand, the research suggests referring to county ecological sensitivity analysis results and further survey county landscape resources in the sensitivity area at varying levels. The whole research area presents a ribbon landscape pattern. In particular, the planning should preserve the integrity of the primitive ecosystem in the most sensitive and high-sensitive areas rich in natural resources, and prohibit excessive city development and construction activities. The medium sensitive area rich in human landscape resources can be properly developed. After all, it is worth noting here that the development should be combined with mountain greening and other landscape construction work. The low-sensitive area rich in mountains and industry villages and towns should keep a good balance of ecological environment and city construction, fully protect the ecological environment, and endeavor to improve people's living environment. Additionally, the planning of Qianxi County should also adhere to the basic principle of ecology priority, make full use of mountain and water resources, and integrate with city features as per local conditions.

\subsection{Qianxi County Featured Landscape Planning}

Qianxi County belongs to the warm temperate and semi-humid region of the monsoon region. The continental monsoon is obvious, and the four seasons are clear, and the precipitation is unevenly distributed throughout the year. The average annual precipitation is $804.2 \mathrm{~mm}$, and the annual maximum precipitation is $1066.4 \mathrm{~mm}$, mostly concentrated in June to August, accounting for more than $70 \%$ of the annual precipitation. The distribution is uneven during the year, and the rainstorm center is easily formed along the Great Wall. Qianxi County is a low-mountain hilly area, with large terrain fluctuations, more mountains, and less land, thereby forming the current landscape of high south and low north. Qianxi County's forest land is full of chestnut trees, rich in forest and fruit resources, and belongs to a typical mountain-type county. Within the territory, there are six major rivers: the Luan River, Sa River, Chang River, Qing River, Heng River, and Huanxiang River. There are 89 gullies in the county with an area of more than 5 square kilometers. Except for the Huanxiang River and its tributaries, $80 \%$ of the county's drainage area is the Luan River system. According to the above analysis results, the paper puts forward four suggestions for Qianxi county landscape planning, including protecting mountain and water resources; reinforcing the development and protection of humanistic tourism resources; maintaining forest land ecology in the northern mountainous area; and improving featured landscape in the county. 
The featured city landscape planning of Qianxi County ought to fully optimize its ecological, natural, and humanistic landscape advantages and highlight city features characterized by the harmonious unity of mountain, water, city, forest, village, and rock. Additionally, it should build an ecological, cultural and habitable city green land system landscape pattern throughout the integration of the city waterfront green land landscape, city road green land landscape and city green land landscape. Especially, the city green land system is supposed to present the unity of mountain, water, the Great Wall, and humanistic resources of Qianxi County. Meantime, it is also essential for Qianxi County to build a featured landscape famous for "verdant mountain, karst water, the Great Wall, and chestnut hometown" which takes mountain and water as the bond, culture as the vein, and green land as the carrier on account of the available greenway network.

Inspired by assessment results, the planning stresses "blue vein" and "green network functions and layout, highlights refinement of ecological factors, and incarnates city natural landscape. In the meantime, it also excavates the history and culture of Qianxi County, generalizes unique city deposits and combines green land planning with city culture. Eventually, Qianxi County builds a landscape structure featured by "one vein and two belts" and "three zones and multiple points" (as shown in Table 6). On the whole, the planning takes Qianxi County as the core, Qingshan Pass as the secondary core, Zhongjing Mountain, Chestnut Orchard, Panjiakou, Xifengkou, Qingshan Pass, Taiping Ancient Rock, Xizhai Relics, Wuhu Mountain, and the Old Lu River Channel as the cornerstone to build a main landscape axis throughout the county. All prime scenic zones and spots are distributed alongside the main axis (as shown in Figure 5).

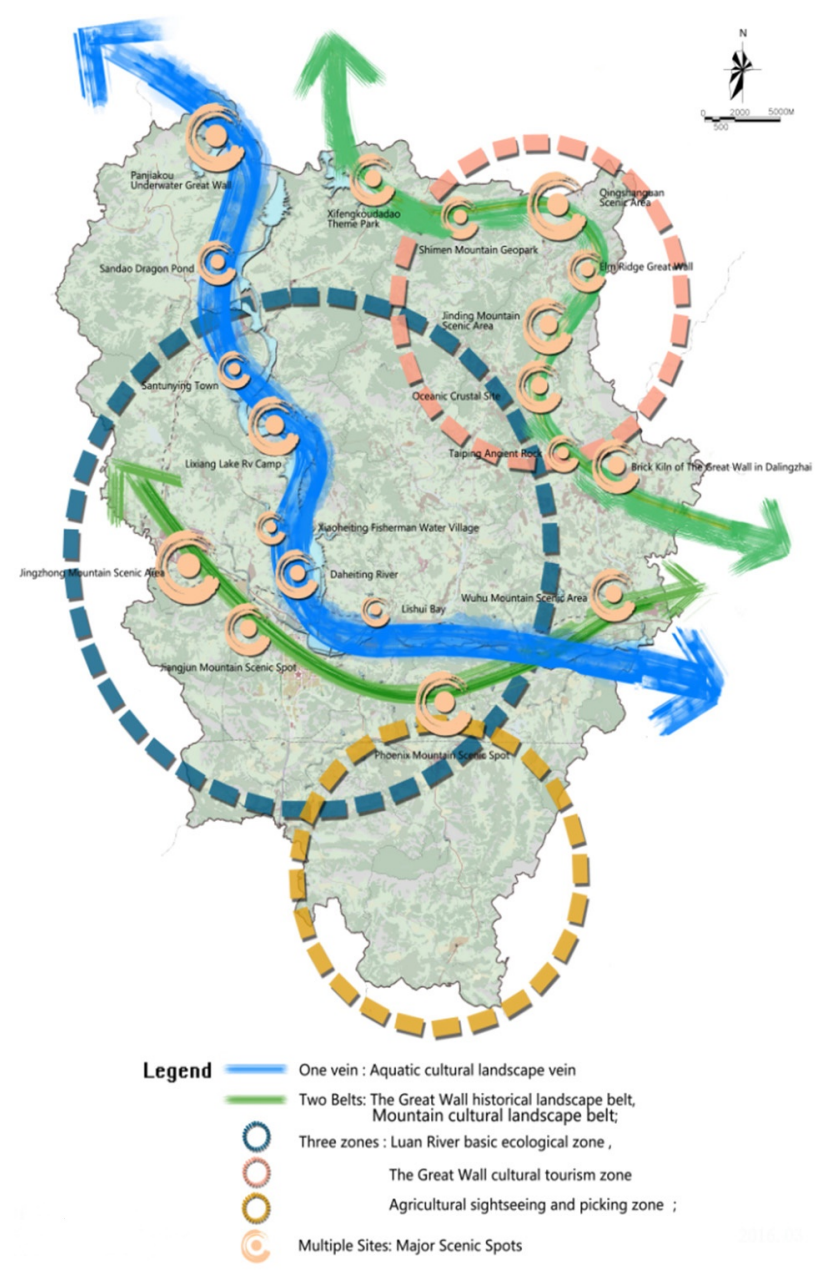

Figure 5. City Featured Landscape Planning Chart. 
Table 6. County Landscape Structure.

\begin{tabular}{|c|c|c|}
\hline Landscape Structure & Planning Division & Route \\
\hline $\begin{array}{l}\text { "one vein and } \\
\text { two belts" }\end{array}$ & $\begin{array}{l}\text { The Great Wall } \\
\text { historical landscape } \\
\text { belt } \\
\text { Mountain cultural } \\
\text { landscape belt }\end{array}$ & $\begin{array}{c}\text { Pajiakou Reservoir- } \\
\text { The Great Wall } \\
\text { Underwater-Lixiang } \\
\text { Lake Leisure Resort - } \\
\text { Xiaoheiting } \\
\text { Fisherman Water } \\
\text { Village-Daheiting } \\
\text { Reservoir-Luan River } \\
\text { Wetland } \\
\text { Xifengkou-Shimen } \\
\text { Mountain-Qingshan } \\
\text { Pass-Yumu Ridge- } \\
\text { oceanic crust relics- } \\
\text { Taiping Ancient } \\
\text { Rock-Great Wall } \\
\text { Brick Kiln in Daling } \\
\text { Village } \\
\text { Jingzhong Mountain- } \\
\text { Jiangjun Mountain } \\
\text {-Fenghuang Mountain } \\
\text {-Wuhu Mountain }\end{array}$ \\
\hline $\begin{array}{l}\text { "three zones } \\
\text { and multiple } \\
\text { points" }\end{array}$ & $\begin{array}{c}\text { Luan River } \\
\text { basic ecological } \\
\text { zone }\end{array}$ & $\begin{array}{l}\text { Build Luan River } \\
\text { Scenic Spot based on } \\
\text { Luan River basin, } \\
\text { Daheiting Reservoir, } \\
\text { Lixiang Lake Leisure } \\
\text { Resort and Luan } \\
\text { River Wetland }\end{array}$ \\
\hline $\begin{array}{l}\text { "three zones } \\
\text { and multiple } \\
\text { points" }\end{array}$ & $\begin{array}{l}\text { Agricultural } \\
\text { sightseeing and } \\
\text { picking zone }\end{array}$ & $\begin{array}{c}\text { Build Great Wall } \\
\text { Scenic Spot based on } \\
\text { Xifengkou, Qinghsan } \\
\text { Pass and Panjiakou } \\
\text { Underwater Great } \\
\text { Wall } \\
\text { Build Ecological } \\
\text { Sightseeing } \\
\text { Agriculture Scenic } \\
\text { Spot based on Yangjia } \\
\text { Valley, Chestnut } \\
\text { Orchard, Donglianhua } \\
\text { Orchard. }\end{array}$ \\
\hline
\end{tabular}

There is a vertical height difference in the mountainous countryside, and the road layout should be freely arranged according to the terrain. The plan will combine the current situation with the needs of villagers and tourism development. The road functions should be defined to create a convenient, fast and unobstructed road system. The lighting facilities on both sides of the road are increased and arranged to combine with the poles. The scale should not be too large, and the shape should be coordinated with the surrounding environment. The street lights of the main road, branch road, and house front road in the village should use street lights of different heights. The fence is best made of natural materials such as wood, stone or hedgerow. It is not suitable to use concrete or brick fences. In planning and designing, the existing water resources of the village are fully used, and the waterfront farmhouse landscape with mountain characteristics is created on both sides of the Chang River tributary. It is necessary to strengthen the improvement of the landscape along the river, protect the water area, and improve the ecological environment of waters. Aquatic plants are appropriately introduced in landscape design, and riverbank treatment should pay attention to plant configuration. The public green space is combined with road green space and courtyard greening to form a greening system that combines lines and surfaces. The tree species configuration makes full use of native tree species to increase survival rates and reduce costs. The combination of deciduous tree species and evergreen tree species forms a good effect of rich layers of the landscape and different scenery step by step, which fully reflects the regional cultural characteristics. 


\section{Discussion}

Affected by urbanization, unplanned development will destroy the rural features and cultural landscapes that have been preserved for thousands of years, and destroy the ecological environment of the countryside. Ultimately, it cannot meet the sustainable development of rural areas. This paper mainly studies the residential landscape planning in Qianxi County, summarizes the main characteristics of the residential landscape in the mountainous and rural areas, as well as analyzes the relationship between the residential landscape and the mountainous environment. Ecological sensitivity refers to the sensitivity of ecosystems to human activities and is used to reflect the possibility of ecological imbalances as well as ecological and environmental problems. Areas with the most sensitive ecological impacts and areas with the most conservation value can be identified by assessing ecological sensitivity, thereby providing a basis for ecological function zoning. Ecological sensitivity is of vital importance to urban-rural planning and local ecological protection [37]. Ecological suitability assessment has been an indicator concept and method used in land-use suitability analysis and assessment. However, the ecological impact assessment method is not applied in construction projects inside the ecological sensitivity area. This paper tentatively comes up with ecological assessment technical proposals for sophisticated ecological environment area and expects to apply it in the preliminary resource assessment system and planning mapping of the mountainous city featured landscape planning. However, the paper chooses a few assessment factors, primarily ecological factors, in Qianxi County. The indicator assessment system should be further improved in follow-up research.

City landscape space is full of complexity and uncertainty. The AHP proves to be restricted in the processing of complexity and uncertainty problems [38-40]. Therefore, although some papers advocate the fuzzy comprehensive assessment method in practice, its drawback of low decision-making efficiency still exists. This method that takes experts' suggestions into consideration is rather subjective. Whereas, it can also reflect important assessment indicators combining with ecological sensitivity assessment. The multi-aspect and multi-layer analysis and assessment of landscape resources help improve the city landscape assessment level.

City planning also involves many other referential factors and complicated contents. The technical assessment system established in this paper is not only applicable for landscape planning, but also applicable for other tourism development, land use planning, and other city planning or green land infrastructure planning. By integrating GIS technology with the AHP in the landscape resource assessment system, the planning designed in the paper can better instruct the progress of the project and solve errors possibly caused by a single assessment method. Different technical routes and assessment systems should be made for different research areas and planning projects. The introduction of GIS technology into the planning and design of mountain landscapes is an inevitable requirement for achieving a scientific and reasonable layout. GIS establishes a spatial data model. Mainly based on the geographic location and spatial data of the processing object, it can analyze the spatial information to establish a spatial data model. As a technology that reflects the dynamic spatial layout relationship between various elements, the fusion of GIS and the AHP can more accurately and scientifically analyze the results more than the AHP method alone, thereby assisting decision-makers in making decisions. GIS is used for quantitative analysis. After systematic analysis of the planned area, factors such as slope, road, river, and building are selected as the main influencing factors for ecological suitability analysis. The Delphi method and the AHP are used to finally determine the weight of each indicator, and the results are divided by the single-factor ecological suitability level. Finally, the GIS single factor assessment is used to carry out a weighted superposition to obtain a comprehensive assessment map of landscape suitability. The assessment results are used to carry out a systematic analysis to conclude the planning strategy of the ecological agricultural sightseeing garden. With the widespread application of GIS, it will provide more scientific and technical support in the field of landscape planning in the future. Simultaneously, the building process of the specific assessment system requires further improvement. Despite the participation of experts, the process of quantifying the indicators is still subjective, which may cause slight deviations in the overall weight of each indicator. 


\section{Conclusions}

GIS technology is a complex discipline newly entering the field of landscape planning. The planning made after carrying out an ecological suitability analysis in the research will certainly have incompleteness. The AHP can be used to estimate a large number of non-quantitative and non-technical factors. The AHP can divide factors into layers according to their affiliation based on their correlation. Then, each factor is compared layer by layer and their relative importance is analyzed to give corresponding quantitative indicators to provide a quantitative basis. The above research shows that city landscape resources may be recognized in a vivid and all-sided manner with GIS technology and the AHP. By way of the analysis and assessment on landscape resources, the planning differentiates areas with varying landscape values, reinforces protection for the ecological environment and landscape resources, effectively avoids damages caused by city development and construction to the city landscape, rationally exploits and utilizes urban landscape resources, and shapes a featured landscape of mountainous Qianxi County. This paper is a scientific attempt for this method. As revealed by research results, as the ecological environment in the longitudinal Luan River system and mountainous topography in Qianxi County is more sensitive, Qianxi County should particularly concentrate on resource protection and use, and recover the ecology in the barren mountain and forest. All villages and towns may exploit tourism resources, as well as arable land and bare land in the plain. This method helps integrate city land and water landscape, and build an ecological, cultural and habitable mountainous city featured landscape pattern.

Author Contributions: Conceptualization, Yanlong Liu.; methodology, Li Li.; writing_original draft preparation, Yanlong Liu.; writing - review and editing, Li Li.; visualization, Yanlong Liu.; supervision, Li Li. All authors have read and agreed to the published version of the manuscript.

Funding: This research received no external funding.

Acknowledgments: We would like to acknowledge the support from Kunsan National University.

Conflicts of Interest: The authors declare no conflict of interest.

\section{References}

1. Gao, Y. An Integrated Analysis of the Charaeteristic Landsepae of the Mountain Area City. Ph.D. Thesis, Tianjin University, Tianjin, China, 2005.

2. Chun-Lan, D. Research of the Discipline of Mounturban Landscape. Ph.D. Thesis, Chongqing University, Chongqing, China, 2005.

3. Liu, H. Research on Evaluation of the Characteristics of Cityscape. Ph.D. Thesis, Suzhou University of Science and Technology, Suzhou, China, 2011.

4. Kevin, L. The Image of the City; Huaxia Publishing House: Beijing, China, 2001.

5. Wei-Zhong, S.; Ying-Bao, Y. Research on Urban Spatial Structure Based on Landscape Ecology; China Science Publishing: Beijing, China, 2007.

6. Taylor, N. The elements of townscape and the art of urban design. J. Urban Des. 1999, 4, 195-209. [CrossRef]

7. Wang, P. Evaluation System and Classified Protection to Chongqing Historic Areas. Ph.D. Thesis, Chongqing University, Chongqing, China, 2009.

8. McHarg, I.L.; Mumford, L. Design with Nature; American Museum of Natural History: New York, NY, USA, 1969.

9. Jian-Guo, G. Landscape Ecology: Patton, Process, Scale and Hierarchy; Higher Education Press: Beijing, China, 2007.

10. Hopkins, L.D. Methods for Generating Land Suitability Maps: A Comparative Evaluation. J. Am. Inst. Planners 1977, 43, 386-400. [CrossRef]

11. Lyle, J.; Stutz, F.P. Computerised land use suitability mapping. Cartogr. J. 1983, 20, 39-49. [CrossRef]

12. Lathrop, R.G.; Bognar, J.A. Applying GIS and landscape ecological principles to evaluate land conservation alternatives. Landsc. Urban Plan. 1998, 41, 27-41. [CrossRef]

13. Marull, J.; Pino, J.; Mallarach, J.M.; José, C.M. A land suitability index for strategic environmental assessment in metropolitan areas. Landsc. Urban Plan. 2007, 81, 212. [CrossRef] 
14. Nguyen, T.T.; Verdoodt, A.; Van, Y.T.; Delbecque, N.; Tran, T.C.; Van Ranst, E. Design of a GIS and multi-criteria based land evaluation procedure for sustainable land-use planning at the regional level. Agric. Ecosyst. Environ. 2015, 200, 1-11. [CrossRef]

15. Min, J. Study on eco-environmental sensitivity evaluation based on gis with ahp. J. Chongqing Norm. Univ. (Nat. Sci. Ed.) 2006, 4, 1-10.

16. Karayalcin, I.I. The analytic hierarchy process: Planning, priority setting, resource allocation. Eur. J. Oper. Res. 1982, 9, 97-98. [CrossRef]

17. Wang, S.-N. Analysis on the Urban Public Facility Location Decision Based on AHP\&GIS. Ph.D. Thesis, Dongbei University of Finance and Economics, Dalian, China, 2016.

18. Bagheri, M.; Azmin, W.N. Application of GIS and AHP Technique for Land-Use Suitability Analysis on Coastal Area in Terengganu. In Proceedings of the 2010 World Automation Congress, Kobe, Japan, 19-23 September 2009.

19. Srdjevic, Z.; Srdjevic, B.; Blagojevic, B.; Bajcetic, R. Combining GIS and Analytic hierarchy process for evaluating land suitability for irrigation: A case study from Serbia. In Proceedings of the 2010 2nd International Conference on Chemical, Biological and Environmental Engineering, Cairo, Egypt, 2-4 November 2010.

20. Parry, J.A.; Ganaie, S.A.; Bhat, M.S. GIS based land suitability analysis using AHP model for urban services planning in Srinagar and Jammu urban centers of J\&K, India. J. Urban Manag. 2018, 7, 46-56.

21. Xiao-Lan, T.; Zhuo-Ran, Z.; Yu, A.N. Landscape resource evaluation based on gis-ahp analysis in xishan traditional villages of Tai lake. J. Gansu Agric. Univ. 2017, 4, 23-30.

22. Zaixu, Z.; Tiejun, Z.; Shuyilang, C.; Youliang, M. Research on mountainous towns' ecological pattern safety assessment based on gis-ahp method:a case study of chongqing new north zone(cnnz). Modern Urban Res. 2014, 8, 22.

23. Yatai Duhui (Beijing) Urban Planning and Building Garden Design Research Institute Co., Ltd. Qianxi County Urban and Rural Planning (2013-2030), Research on Tourism Development; Qianxi County Government: Qianxi, China, 2014.

24. Nanjing Forestry University Engineering Planning and Design Institute Co., Ltd. Qianxi County Urban Green Space System Planning (2016-2030); Qianxi County Government: Qianxi, China, 2017.

25. Yanshan University Tourism Development Research Center. Qianxi County, Hebei Province Tourism Development overall Plan Revision (2016-2025); Qianxi County Government: Qianxi, China, 2016.

26. Yao, S.; Wei, Z.; Jingming, R.; Jianping, Z. Ecological suitability assessment and eco-mapping for tourism development in an eco-sensitive region. Acta Ecol. Sin. 2015, 35, 7887-7898.

27. Bozdağ, A.; Yavuz, F.; Günay, A.S. AHP and GIS based land suitability analysis for Cihanbeyli (Turkey) County. Environ. Earth Sci. 2016, 75, 813. [CrossRef]

28. Yalew, S.G.; Van Griensven, A.; Mul, M.L.; Pieter, V.D.Z. Land suitability analysis for agriculture in the abbay basin using remote sensing, gis and ahp techniques. Model. Earth Syst. Environ. 2016, 2, 101. [CrossRef]

29. Pramanik, M.K. Site suitability analysis for agricultural land use of Darjeeling district using AHP and GIS techniques. Model. Earth Syst. Environ. 2016, 2, 56. [CrossRef]

30. Huichao, S. Ecological sensitivity analysis and evaluation of Quanjiao County base gis. Planners 2015, S2, 32-38.

31. Liang-Juan, W. The Ecological Sensitivity Analysis of Lang Mountain Scenic Area's Research on Protection and Utilize. Ph.D. Thesis, Central South University of Forestry and Technology, Changsha, China, 2016.

32. Guoan, T.; Xi, Y. ArcGIS Geographic Information System Spatial Analysis Experimental Course; Science Press: Guangzhou, China, 2006.

33. Saaty, T.L. The Analytical Hierarchy Process; McGraw Hill Process: New York, NY, USA, 1980.

34. Ying, X.; Zeng, G.-M.; Chen, G.-Q.; Tang, L.; Wang, K.-L.; Huang, D.-Y. Combining AHP with GIS in synthetic evaluation of eco-environment quality-A case study of Hunan Province, China. Ecol. Model. 2007, 209, 97-109. [CrossRef]

35. Chakraborty, S.; Banik, D. Design of a material handling equipment selection model using analytic hierarchy process. Int. J. Adv. Manuf. Technol. 2006, 28, 1237-1245. [CrossRef]

36. Chen, Y.; Yu, J.; Khan, S. Spatial sensitivity analysis of multi-criteria weights in GIS-based land suitability evaluation. Environ. Model. Softw. 2010, 25, 1582-1591. [CrossRef]

37. Collins, M.G.; Steiner, F.R.; Rushman, M.J. Land-Use Suitability Analysis in the United States: Historical Development and Promising Technological Achievements. Environ. Manag. 2001, 28, 611-621. [CrossRef] 
38. Saaty, T.L.; Tran, L.T. On the Invalidity of Fuzzifying Numerical Judgments in the Analytic Hierarchy Process; Elsevier Science Publishers B.V.: Amsterdam, The Netherlands, 2007.

39. Kordi, M.; Brandt, S.A. Effects of increasing fuzziness on analytic hierarchy process for spatial multicriteria decision analysis. Comput. Environ. Urban Syst. 2012, 36, 43-53. [CrossRef]

40. Mosadeghi, R.; Warnken, J.; Tomlinson, R.; Mirfenderesk, H. Comparison of Fuzzy-AHP and AHP in a spatial multi-criteria decision making model for urban land-use planning. Comput. Environ. Urban Syst. 2015, 49, 54-65. [CrossRef]

(C) 2020 by the authors. Licensee MDPI, Basel, Switzerland. This article is an open access article distributed under the terms and conditions of the Creative Commons Attribution (CC BY) license (http://creativecommons.org/licenses/by/4.0/). 